\title{
Nasal septum mucocele in a patient with two other mucoceles of the paranasal sinuses: late complications of maxillofacial trauma*
}

A. Fontes Lima, F. Carvalho Moreira, C. Azevedo, S. Vilarinho

Department of Otorhinolaryngology and Head and Neck Surgery, Hospital de Braga, Braga, Portugal
Rhinology Online, Vol 3: 152 - 156, 2020

http://doi.org/10.4193/RHINOL/20.055

*Received for publication:

July 6, 2020

Accepted: September 18, 2020

Published: October 2, 2020

\begin{abstract}
Introduction: Mucoceles are pseudocystic lesions that, despite being benign, may cause diverse symptoms related to its expansive nature. Although their most common location in the nose is the frontoethmoidal sinuses, they can occur in other sites. The authors present a case of a patient with a nasal septum mucocele besides mucoceles in other locations, reviewing the literature regarding these entities.
\end{abstract}

Case presentation: The patient, who had a history of a previous major maxillofacial trauma, was referred to Otorhinolaryngology evaluation because of a long-standing history of nasal obstruction. On nasal endoscopy, a bilateral posterior nasal septum bulging at the choanae level was observed; an irregularity on the external wall of the maxillary sinus was noted in the palpation of the midface. Computed tomography (CT) showed a posterior nasal septum hypodense lesion besides two other lesions with similar features, one in the maxillary sinus, and another in the anterior ethmoid. A magnetic resonance imaging followed, and confirmed the lesions, that were hyperintense in $\mathrm{T} 1$ and did not show enhancement with gadolinium. A surgical approach, namely marsupialization through endoscopic sinus surgery, was performed. Histopathology confirmed the three lesions as mucoceles. The patient reported nasal obstruction complaints resolution; he has been in follow-up with no signs of relapse.

Discussion and conclusion: Despite being extremely rare, nasal septum mucoceles should be remembered when evaluating midline nasal lesions, and included in the differential diagnosis. When evaluating patients with a history of major maxillofacial trauma other atypical findings may be present.

Key words: mucocele, nasal septum mucocele, midline nasal lesion, nasal obstruction

\section{Introduction}

Paranasal sinus mucoceles are relatively common lesions. Several factors may predispose to its development, of which previous nasal surgery and trauma are the most frequent, but also radiotherapy, rhinosinusitis, and cystic fibrosis ${ }^{(1)}$. Although their most common location in the nose is the frontalethmoidal sinuses, they can occur in other parts of the nasal cavities or paranasal sinuses.

The authors report a case of a patient with multiple mucoceles, one with an extremely rare location, the nasal septum (NS).

\section{Case presentation}

A 49-year-old male presented for Otorhinolaryngology evaluation complaining of bilateral chronic nasal obstruction, that had begun several years before and did not improve with local medical therapy. He had a history of major maxillofacial trauma in a car accident 24 years before, with multiple fractures that needed surgical correction, besides right eye enucleation; he had a complete visual loss of the left eye. He had multiple scars on the skin of the nose and malar region. On nasal endoscopy, there was a posterior bilateral bulging of the NS, covered by normal mucosa, that reached the level of the choanae (Figure 1). 

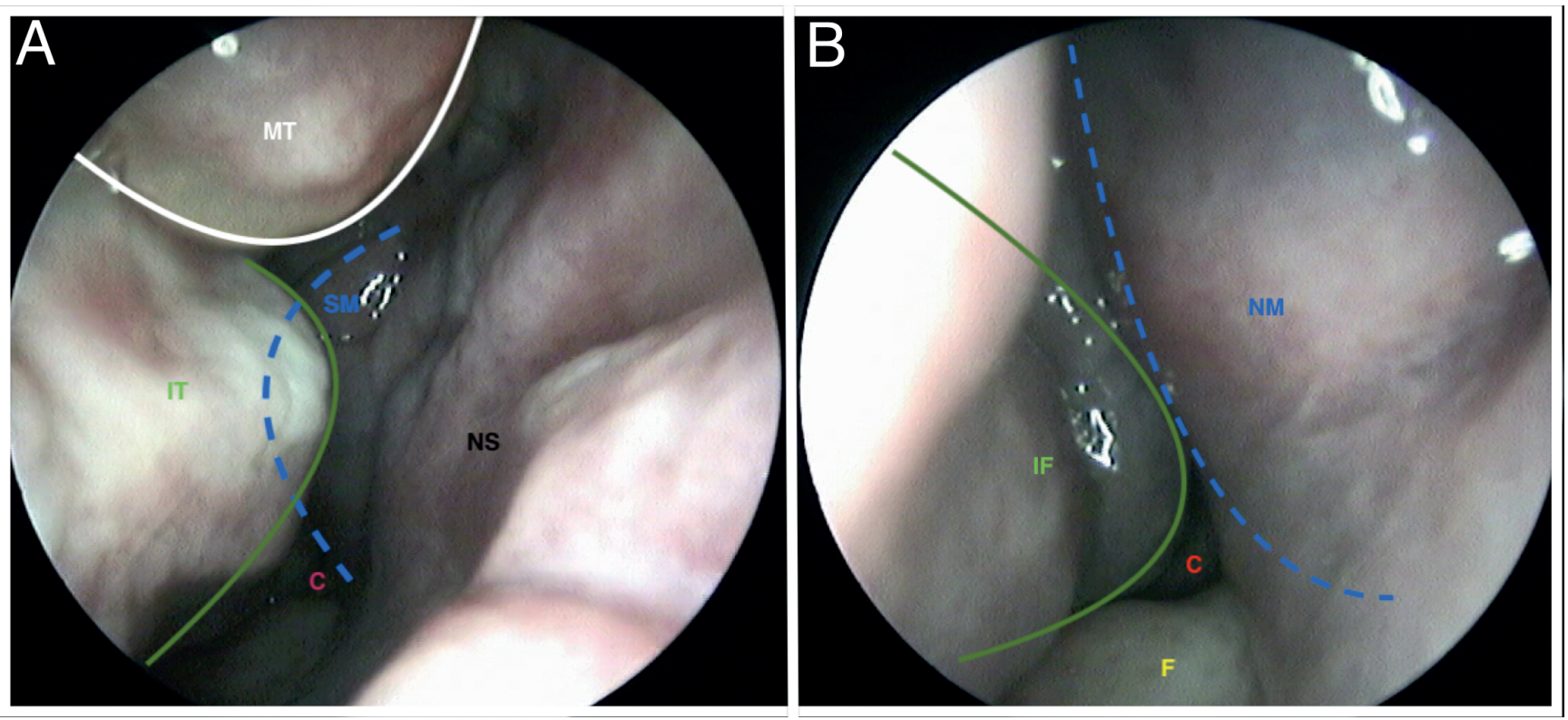

Figure 1. Nasal endoscopy on the right nostril showing obliteration of the choanae (IT: inferior turbinate; MT: middle turbinate; NS: nasal septum; SM: septal mucocele; C: choanae; F: floor of the nose).
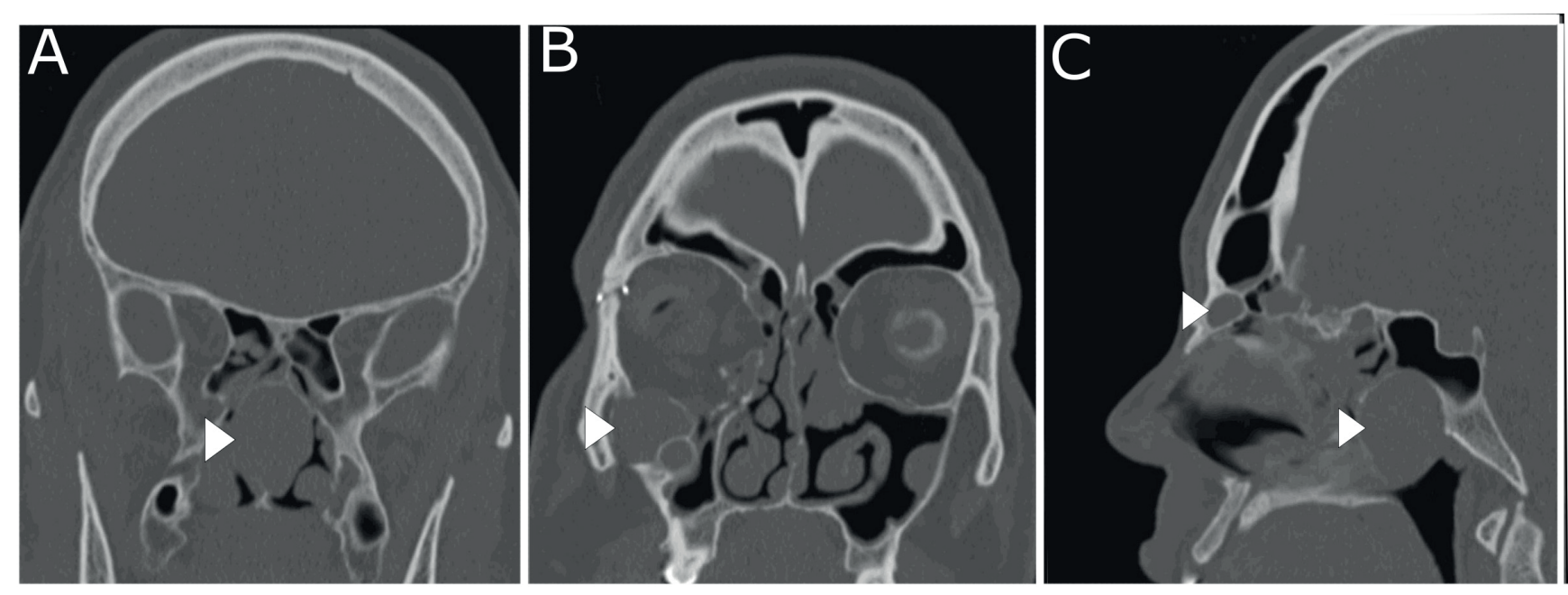

Figure 2. Computed tomography in the coronal (A and B) and sagittal planes $(C)$ showing the following hypodense lesions: nasal septum lesion (A and C); maxillary lesion (B); anterior ethmoid lesion (C).

This midline lesion caused significant impairment of nasal permeability. There was also a deformity of the middle meatus on the right side. Irregularity of the lateral wall of the right maxillary sinus was perceptible in the palpation of the midface. The patient underwent CT scan (Figure 2) which revealed signs of previous major maxillofacial trauma and reconstructive surgery, with prosthetic material in both lateral walls of the orbit, and phthisis bulbi of the left eye; besides, a hypodense septal lesion was observed, which deformed and eroded antero-inferiorly the sphenoid sinus, namely the sphenoid's rostrum, and partially obstructed choanae bilaterally; another lesion with similar features was found on the right maxillary sinus, which eroded the lateral and posterior wall of the maxillary sinus and protruded to the infratemporal fossa; another analogous lesion was found in the right ethmoid, namely in the agger nasi cell. The CT scan was followed by a magnetic resonance imaging (MRI). The MRI confirmed those lesions, which were hyperintense in T1 and did show enhancement with gadolinium, and were suggestive of mucoceles (Figure 3).

He underwent endoscopic sinus surgery with marsupialization of all the three mucoceles with drainage of mucoid content from all of them. The patient's nose was packed with absorbable gelfoam in both nasal cavities. The postoperative period was uneventful. Histopathologic analysis of the capsules of the different lesions was compatible with respiratory epithelium, which led to the diagnosis of mucoceles. In the follow-up consultations, the 

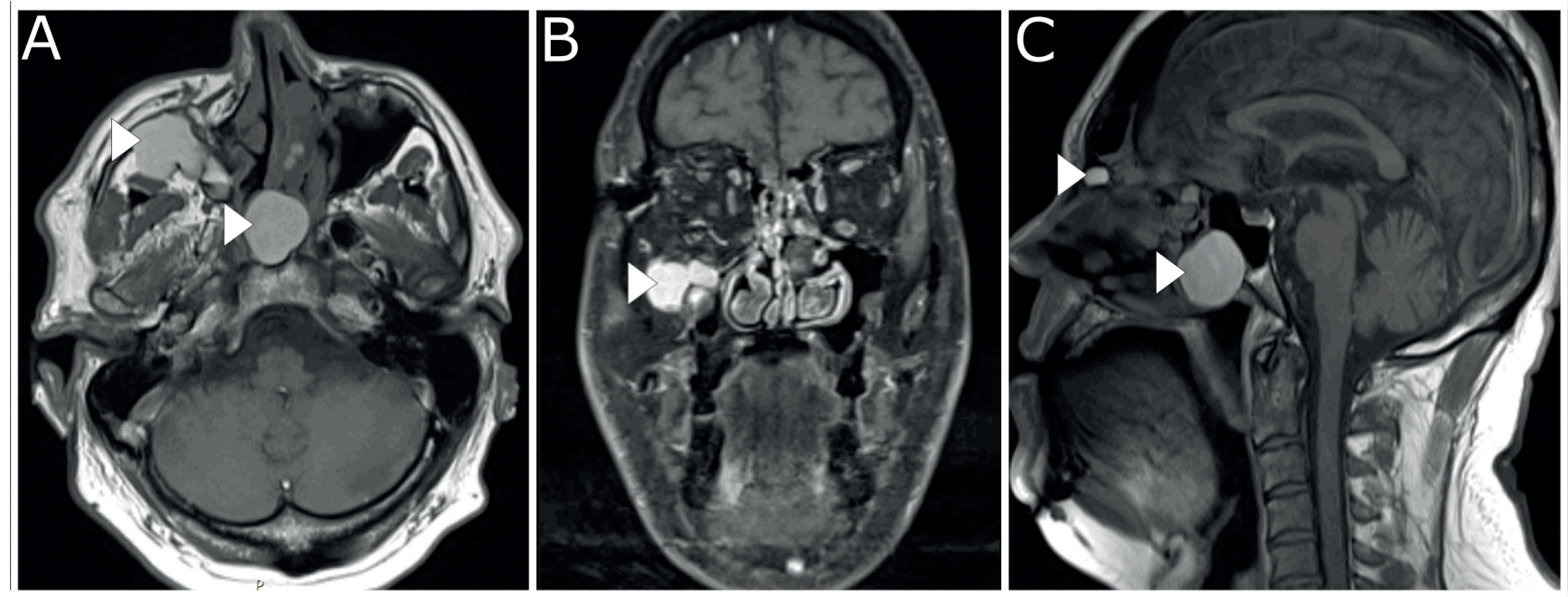

Figure 3. Magnetic resonance imaging in $\mathrm{T} 1$ in axial (A), sagittal (B) and coronal (C) planes showing hyperintense lesions: nasal septum lesion (A and C); maxillary lesion (A and B); anterior ethmoid (C).

Table 1. Previously reported septal mucoceles in the literature (yo: year old).

\begin{tabular}{|c|c|c|c|c|c|}
\hline & Gender & Age & Risk Factors & Symptoms at presentation & Treatment \\
\hline Gall and Witterick ${ }^{(4)}$ & Male & 62 yo & Nasal surgery (septoplasty) & Nasal obstruction & Endoscopic Marsupialization \\
\hline Hermann and Jahnke ${ }^{(2)}$ & Male & 54 yo & Nasal surgery (FESS) & $\begin{array}{l}\text { Facial pain located in the } \\
\text { infraorbital region }\end{array}$ & Endoscopic Marsupialization \\
\hline Lei et al. ${ }^{(11)}$ & Male & 37 yo & $\emptyset$ & Enlarging painful nasal mass & Endoscopic marsupialization \\
\hline Taskin et al. ${ }^{(3)}$ & Male & 45 yo & $\emptyset$ & Bilateral nasal obstruction & Endoscopic complete excision \\
\hline Aynali et al. (14) & Male & 34 yo & $\begin{array}{l}\text { Nasal surgery (rhinoplasty) } 15 \\
\text { years before }\end{array}$ & Bilateral nasal obstruction & Endoscopic complete excision \\
\hline Lo Casto et al. (5) & Male & 49 yo & $\begin{array}{l}\text { Nasal surgery (FESS for frontal } \\
\text { mucocele excision) }\end{array}$ & Bilateral nasal obstruction & Endoscopic marsupialization \\
\hline Akidil et al. ${ }^{(9)}$ & Male & 13 yo & $\emptyset$ & Nasal obstruction & Endoscopic complete excision \\
\hline Lee et al. ${ }^{(6)}$ & Female & 52 yo & $\emptyset$ & Headache & Endoscopic marsupialization \\
\hline Hong et al. ${ }^{(7)}$ & Male & 52 yo & $\begin{array}{l}\text { Maxillofacial trauma } 35 \text { years } \\
\text { before }\end{array}$ & Bilateral nasal obstruction & Endoscopic marsupialization \\
\hline Ghorbani et al. ${ }^{(10)}$ & Male & 27 yo & $\begin{array}{l}\text { Nasal surgery (septoplasty and } \\
\text { turbinoplasty) } 5 \text { years before }\end{array}$ & $\begin{array}{l}\text { Nasal obstruction and frontal } \\
\text { headache }\end{array}$ & Endoscopic marsupialization \\
\hline Rawl et al(8) & Male & 57 yo & $\begin{array}{l}\text { Nasal surgery ( } 3 \text { times) after } \\
\text { nasal trauma } 35 \text { years before }\end{array}$ & Nasal obstruction & $\begin{array}{l}\text { External approach (modified } \\
\text { Killian incision) with complete } \\
\text { excision }\end{array}$ \\
\hline
\end{tabular}

patient reported resolution of all complaints, and no relapse was diagnosed.

\section{Discussion}

NS mucoceles are extremely rare entities and, in the literature, there are only 11 other reported cases (Table 1). As in the case presented, most of the reports refer to middle-aged male patients ${ }^{(2-8)}$. Nonetheless, there are some younger patients, including one in the pediatric age $\mathrm{e}^{(9,10)}$.

While some cases had no previous relevant risk factors, most of the patients had undergone nasal surgery in the past, and one had a history of maxillofacial trauma several years before, as in the case reported in this paper.

There are two main explanations to mucocele formation of the NS: the first is related to the rare occurrence of a pneumatized $\mathrm{NS}^{(11)}$. The NS, that extends anteriorly from the columella and posteriorly to the rostrum of the sphenoid sinus, includes three components, the membranous septum, the cartilaginous septum, and the bony septum, the latter consisting of the perpendicular plate of the ethmoid and the vomer ${ }^{(12)}$. Septal pneumatization, more common in the perpendicular plate of the ethmoid, has a variable reported prevalence, ranging from as low as 0,5 to 
Table 2. Previously reported patients with multiple mucoceles in the literature (yo: year old).

\begin{tabular}{|c|c|c|c|c|c|c|}
\hline & Gender & Age & Risk factors & $\begin{array}{l}\text { Symptoms at } \\
\text { presentation }\end{array}$ & Mucocele location & Treatment \\
\hline Price et al. ${ }^{(17)}$ & Female & 56 yo & $\begin{array}{l}\text { Maxillofacial } \\
\text { trauma }\end{array}$ & $\begin{array}{l}\text { Proptosis and } \\
\text { diplopia }\end{array}$ & $\begin{array}{l}\text { Left frontal sinus, ethmoid bilaterally, } \\
\text { sphenoid sinus, maxillary sinus }\end{array}$ & Not described \\
\hline Sadoff et al. ${ }^{(15)}$ & Female & 21 yo & $\emptyset$ & $\begin{array}{l}\text { Cellulitis of the eye } \\
\text { and malar region }\end{array}$ & Maxillary sinus bilaterally & $\begin{array}{l}\text { External approach } \\
\text { (anterior antrostomy) }\end{array}$ \\
\hline Thomé et al. ${ }^{(18)}$ & Male & $\begin{array}{c}10 \\
\text { months }\end{array}$ & Cystic fibrosis & Nasal obstruction & Ethmoid bilaterally & $\begin{array}{l}\text { Endoscopic } \\
\text { marsupialization }\end{array}$ \\
\hline Varghese et al. ${ }^{(16)}$ & Female & 65 yo & $\emptyset$ & $\begin{array}{l}\text { Proptosis and } \\
\text { swelling of the } \\
\text { middle canthus }\end{array}$ & $\begin{array}{l}\text { Anterior ethmoid (right) and maxillary } \\
\text { sinus (left) }\end{array}$ & $\begin{array}{l}\text { Endoscopic } \\
\text { marsupialization }\end{array}$ \\
\hline $\begin{array}{l}\text { Berlucchi and Reda- } \\
\text { elli de zinis }{ }^{(1)}\end{array}$ & Female & 3 yo & $\emptyset$ & Proptosis & $\begin{array}{l}\text { Maxillary bilaterally and ethmoid } \\
\text { bilaterally }\end{array}$ & $\begin{array}{l}\text { Endoscopic } \\
\text { marsupialization }\end{array}$ \\
\hline
\end{tabular}

as high as $18 \%$ of the population ${ }^{(10)}$. Some authors advocate that the obstruction of this pneumatized septum is usually a consequence of trauma or inflammation and that this is the primary event that leads to mucocele formation. The second hypothesis refers to the entrapment of mucosa in the septum after surgery of trauma ${ }^{(4,10)}$. The latter hypothesis is more controversial given how rare it is, for example, after septal surgery ${ }^{(10)}$. In the case presented it is not easy to determine the precise pathophysiology of the lesion, specifically the location where the mucocele started developing. Still, given its NS postero-inferior location, the authors hypothesize it probably initiated at the level of the vomer and expanded anteriorly and posteriorly, caused the observed bulging of the NS that consequently led to the nasal obstruction complaints, and partially eroded antero-inferiorly the sphenoid sinus, namely its anterior wall and rostrum. Another possible explanation would be that the mucocele started at the rostrum/anterior wall of the sphenoid sinus itself, and grew and eroded the vomer anteriorly, causing the findings described. The reported patient presented with bilateral nasal obstruction as the main symptom, which was related to the septal mucocele that obstructed the choanaes. There are important differences between the clinical presentation of NS mucoceles and mucoceles in different locations: NS mucoceles usually present earlier than in other locations, given the common impairment they cause in nasal permeability, producing nasal obstruction complaints. Nasal obstruction is, according to our review, the most common form of presentation of NS mucoceles $s^{(3,5-7,10,13,14)}$. On the other hand, it is not a common symptom at presentation amongst patients with mucoceles in other locations ${ }^{(10)}$.

The differential diagnosis of septal mucoceles depends on its exact location and includes midline nasal masses, such as nasal gliomas, nasal encephaloceles, neuroblastoma, nasal dermoid cysts, epidermoid cyst, hemangioma, lymphangiomas, angiofibromas, and also septal abscess and foreign bodies ${ }^{(8)}$.

The reported case is unique for another reason: while there are several cases in the literature describing mucoceles which individually are responsible for the erosion of multiple paranasal sinuses, literature is scarce in what refers to multiple individual mucoceles in the same patient. There are only other five cases described of multiple mucoceles (Table 2). Most of the patients reported are female, with no identified risk factors for mucoceles ${ }^{(1,15,16)}$. There are exceptions: one newborn with cystic fibrosis (CF), and one patient with previous major maxillofacial trauma, as in our case $\mathrm{e}^{(17,18)}$. The clinical presentation is variable according to the locations of the mucoceles; nevertheless, given the ethmoid is affected in the majority of cases, ophthalmologic symptoms are common ${ }^{(1,16,17)}$. Differential diagnosis of multiple mucoceles includes mucous retention cysts, polyostotic fibrous dysplasia, multiple myeloma, and aneurysmal bone cyst $^{(15)}$. In the evaluation of nasal lesions, CT scan, and MRI both have an important role ${ }^{(19)}$. Mucoceles are usually round hypodense lesions in CT scan commonly associated with sinus wall expansion and erosion ${ }^{(8,16,18)}$. Nonetheless, mucocele may have a similar appearance to other benign lesions with CT scans. MRI, on the other hand, can help differentiate mucoceles from other lesions, assess intracranial and intraorbital extension and involvement. The intensity in MRI is variable according to the protein concentration in the secretions and presence of infection and can vary over time ${ }^{(19)}$. With time, protein concentration tends to increase; a recent mucocele may be hypointense in $\mathrm{T} 1$ and hyperintense in $\mathrm{T} 2$, while a long-evolving mucocele may be hyperintense in $\mathrm{T} 1$ and hypointense in $\mathrm{T} 2^{(19)}$. Besides, using contrast (such as gadolinium) will only enhance the periphery of the lesion and not its content.

Mucocele treatment has been changing throughout the years ${ }^{(20)}$. Marsupialization through endoscopic surgery has gained acceptance with time: it creates a perfectly aerated sinus, easy to examine in the postoperative period, and reduces the need for exams. It is suitable for almost all mucocele locations, and, in our case, we were able to treat effectively all of them. External approaches are still valuable in some situations, such as revision cases, laterally located frontal mucoceles, extensive erosion of 
the external plate of the frontal sinus, and intracranial complications (for example, subdural empyemas) ${ }^{(20)}$. Regardless of the chosen approach, given mucoceles' tendency for relapse, a long follow-up is desirable.

\section{Conclusions}

Although extremely rare, NS mucocele should be considered in the differential diagnosis of midline nasal masses, especially if there is a history of maxillofacial trauma or septal surgery. Other atypical findings may emerge as a consequence of complex maxillofacial trauma. In our case, besides the unusual finding of a NS mucocele, other mucoceles were present, giving physical examination and imaging a relevant role in the evaluation of these patients.

\section{Acknowledgments}

None

\section{Authorship contribution}

AFL wrote the manuscript. FCM, CA, and SV critically revised the manuscript. All authors read and approved the final manuscript.

\section{Conflict of interest}

The authors declare that there is no conflict of interest.

\section{Ethics approval}

Not applicable.

\section{Consent for publication}

Written informed consent for publication of clinical details and clinical images was obtained from the patient in question.

\section{Availability of data and materials Not applicable.}

\section{Funding}

The authors declare no conflict of interest.

\section{References}

1. Berlucchi M, Redaelli de Zinis LO. Multiple paranasal mucoceles in a child. Arch Dis Child. 2018 Feb;103(11):314-25.

2. Hermann P, Jahnke K. Raumforderung des Septum nasale bei Patientin mit linksseitigem Gesichtsschmerz. HNO. 2002 Jun 1;50(6):570-1.

3. Taskin U, Korkut YA, Aydn S, Oktay FM Atypical Presentation of Primary Giant Nasal Septal Mucopyocele. J Craniofac Surg. 2012 Jan;23(1):e5-7.

4. Gall R, Witterick I. Mucocele of the Nasal Septum. J Otolaryngol [Internet]. 2002;31(04):246. Available from: http:// journals.bcdecker.com/CrossRef/showText.aspx?path=JOT/volume 31\%2C 2002/ issue 04\%2C August/jot_2002_21184/ jot_2002_21184.xml

5. Lo Casto A, Lorusso F, Lombardo F, Speciale R. Secondary septal mucocele diagnosed by MRI and CBCT and treated surgically. B-ENT. 2014;10(3):221-5.

6. Lee DH, Lee JJW, Cho WS, Lim SC. Mucocele of the Nasal Septum: Case Report and Review of the Literature. J Rhinol. 2015;22(2):112.

7. Hong S-A, Kim T, Wu HW, Kim HJ. A Case of Mucocele Occurred in Nasal Septum. Korean J Otorhinolaryngol Neck Surg. 2016;59(2):170.

8. Rawl JW, Rossi NA, Chaaban MR, Brindley P. Intraseptal Mucocele as a Long-term
Complication of Revision Septorhinoplasty: A Case Report and Review of a Rare Entity. Allergy Rhinol. 2019 Jan 29;10:1-5.

9. Akidil AO, Sinan M, Guven M. Paranasal Sinus Mucoceles: Report of Cases in Four Different Localisations, Two of Which are Uncommon. Firat Tıp Derg. 2014;17:23-6.

10. Ghorbani J, Doraghi K. Nasal Septal Mucocele, Presenting as Nasal Midline Mass. 2019;4:2-5. Available from: http:// anncaserep.com/

11. Lei L, Wang R, Han D. Pneumatization of perpendicular plate of the ethmoid bone and nasal septal mucocele. Acta Otolaryngol. 2004 Mar 8;124(2):221-2.

12. Georgalas C, Fokkens W. Rhinology and Skull Base Surgery: From the Lab to the Operating Room - An Evidence-based Approach. 1st Ed. Thieme; 2013.

13. Gall R, Witterick I. Mucocele of the nasal septum. J Otolaryngol. 2002;31(4):246-7.

14. Aynali G, Sivrice $M E$, Ünal F, Doğan $M$, Ünlü EN, Yarıktaş M. A Giant Mucocele of Nasal Septum: Case Report and Literature Review. J Clin Anal Med. 2013;4(suppl 1):13.

15. Sadoff RS, Rubin MM. Bilateral antral mucoceles: A report of a case. J Oral Maxillofac Surg. 1991 Feb;49(2):193-6.

16. Varghese $L$, John M, Kurien M. Bilateral Asymmetric Mucoceles of the Paranasal Sinuses: A First Case Report. Ear, Nose Throat J. 2004 Dec 16;83(12):834-5.
17. Price HI, Batnitzky S, Karlin CA, Norris CW. Multiple Paranasal Sinus Mucoceles. J Comput Assist Tomogr. 1981 Feb;5(1):122-5.

18. Thomé DC, Voegels RL, Cataldo de la Cortina RA, Butugan O. Bilateral ethmoidal mucocele in cystic fibrosis: report of a case. Int J Pediatr Otorhinolaryngol. 2000 Sep;55(2):143-8.

19. Bouatay R, Aouf L, Hmida B, Korbi A El, Kolsi $N$, Harrathi $K$, et al. The role of imaging in the management of sinonasal mucoceles. Pan Afr Med J. 2019;34:1-8.

20. Lima AF, Moreira FC, Miranda D, Silva D, Costa I, Dias L. Mucocelos fronto-etmoidais: Pearls \& pitfalls na abordagem terapêutica. Rev Port Otorrinolaringol E Cir Cabeça E Pescoço. 2018;56:107-11.

Antonio Fontes Lima Department of Otorhinolaryngology and Head and Neck Surgery Hospital de Braga Braga Portugal

Tel: +351912395978

E-mail:

Antoniofonteslima24@gmail.com

ISSN: 2589-5613 / @2020 The Author(s). This work is licensed under a Creative Commons Attribution 4.0 International License. The images or other third party material in this article are included in the article's Creative Commons license, unless indicated otherwise in the credit line; if the material is not included under the Creative Commons license, users will need to obtain permission from the license holder to reproduce the material. To view a copy of this license, visit http://creativecommons.org/ licenses/by/4.0/ 